\title{
"Mar de Lama": O Anticomunismo como oposição ao Trabalhismo nas eleições de 1958 no Rio Grande do Sul
}

\author{
"Mar de Lama": The Anticommunism in opposition to the Labour in the 1958 elections \\ in Rio Grande do Sul
}

\author{
Carla Renata Antunes de Souza Gomes* \\ renata.asg@terra.com.br \\ Samuel da Silva Alves** \\ samuel.alves13@outlook.com \\ Tiago de Moraes Kieffer*** \\ tiagodekieffer@gmail.com
}

Resumo: Este artigo propõe uma análise acerca das estratégias anticomunistas utilizadas pela Frente Democrática, apoiadora do candidato Walter Peracchi Barcelos, contra o trabalhismo de Leonel de Moura Brizola nas eleições ao Governo do Estado do Rio Grande do Sul no ano de 1958. Nosso ponto de partida é um poema, intitulado $O$ Mar de Lama, que contém informações relativas ao início do trabalhismo na Europa, acusações contra o PTB e suas alianças políticas, ao passado do fundador e maior nome do partido - Getúlio Vargas - como ditador do Estado Novo, além de insinuações quanto ao parentesco de Leonel Brizola com o então Vice Presidente João Goulart, de ligações do candidato petebista ao Partido Comunista e panfletos de apoio, por parte de órgãos públicos, como a Brigada Militar, representada por seus oficiais, ao candidato Walter Peracchi Barcelos. Seguiremos no campo da Nova História Política, baseados nos conceitos de Cultura Política e Imaginário Anticomunista, para assim identificar a ideologia dos atores envolvidos na eleição e as estratégias utilizadas para o combate do outro, o qual, na maioria das vezes, era identificado ou associado a grupos comunistas. A partir desta análise, entendemos o anticomunismo não como convicção ideológica neste momento, mas como discurso de mobilização das massas, utilizado pela Frente Democrática com o intuito de denegrir a campanha trabalhista frente ao eleitorado rio-grandense e a instituições como a Igreja Católica, além de colocar o candidato da Frente Democrática em um patamar de combatente ao perigo que o Comunismo representava à sociedade do Rio Grande do Sul.

Palavras-Chave: anticomunismo, trabalhismo, Brizola

Abstract: This article proposes an analysis of the strategies used by the "Frente Democrática", supporter of the candidate Walter Peracchi Barcelos, against the labour of Leonel de Moura Brizola in the elections to the State Government of Rio Grande do Sul State in 1958. Our starting point is a poem, entitled $O$ Mar de Lama containing information on the initiation of Labour in Europe, charges against the PTB and its political alliances, the past founder and biggest name of the party - Getulio Vargas - as dictator of the Estado Novo, as well insinuations about the relationship of Leonel Brizola with then Vice President Joao Goulart, of PTB candidate links to the Communist party and support pamphlets, by public bodies such as the Military Police, represented by its officers, to the candidate Walter Peracchi Barcelos. We will continue in the field of New Political History, based on the concepts of Political Culture and anticommunist imaginary, thus identifying the ideology of the actors involved in the election and the strategies used to fight each other, which, in most cases, was identified or associated the communist groups. From this analysis, we understand the anticommunism not as ideological conviction at this point, but as mobilization speech of the masses, used by the "Frente Democratica" in order to denigrate the labour front campaign to the rio-grandense electorate and institutions like the Catholic Church, and put the candidate of the "Frente Democrática" in a fighter level of the danger that Communism represented the Rio Grande do Sul's society.

Keywords: anticommunism, labour, Brizola

\footnotetext{
*Doutora em História pela Universidade Federal do Rio Grande do Sul. Professora de graduação em História e no Programa de Pós Graduação Mestrado e Doutorado de Memória Social e Bens Culturais do Centro Universitário La Salle (Unilasalle).

**Acadêmico do curso de licenciatura em História pelo Centro Universitário La Salle (Unilasalle).

***Acadêmico do curso de licenciatura em História pelo Centro Universitário La Salle (Unilasalle).
} 


\section{Introdução}

O cenário político sul rio-grandense após o fim do Estado Novo, em 1945, é marcado por limitações entre as ideologias simpatizantes com a esquerda soviética e com o conservadorismo estadunidense. Até 1964, com o golpe militar que tiraria da presidência João Goulart, a política brasileira fora marcada pela ambiguidade - líderes carismáticos, participação popular através do voto direto - e como um espelho das decisões internacionais, refletia na sua realidade a Guerra Fria e a influência dos blocos presentes na mesma.

As fronteiras são tênues: como conceituar se partidos como o Partido Trabalhista Brasileiro (PTB) eram de esquerda? Como explicar o apoio dos comunistas ao queremismo - movimento contra a deposição de Getúlio Vargas, criador do PTB - em 1945, ou na eleição de 1951? E à Brizola para a Prefeitura de Porto Alegre em 1955? A ambiguidade ocorre quando, na eleição para o Executivo do Rio Grande do Sul, em 1958, ao mesmo tempo em que o líder do Partido da Representação Popular (PRP), Plínio Salgado ${ }^{1}$, apoia o candidato Leonel de Moura Brizola contra o perigo que representava o comunismo, Luis Carlos Prestes ${ }^{2}$, principal nome do Partido Comunista Brasileiro (PCB), publica uma nota de apoio à Brizola, apesar da já declarada ligação entre PTB e PRP, seguida da não aceitação de tal apoio por parte do candidato trabalhista, em virtude de uma possível perda de votos junto ao eleitorado católico e setores conservadores. A proposta desse artigo não é refletir acerca da sinceridade dos jogos políticos do período, tampouco criar fronteiras entre a direita e a esquerda da época. Contudo, iremos analisar um caso específico: a candidatura de Walter Peracchi Bar- $\operatorname{celos}^{3}$ e a propaganda anticomunista contra o trabalhismo de Leonel de Moura Brizola.

Nosso ponto de partida é uma trova intitulada $O$ Mar de Lama ${ }^{4}$, que contém informações sobre a origem do trabalhismo, acusações contra o PTB e suas alianças políticas, insinuações de ligação do candidato petebista com o PCB, assim como a ação nostálgica de relembrar as perseguições realizadas aos imigrantes alemães e italianos no período do Estado Novo. Procuramos responder as questões sobre as estratégias anticomunistas contra o trabalhismo nos baseando, além da trova já citada, em acervos particulares, como os de Walter Peracchi Barcelos, Hamilton Moojen Chaves e Francisco Brochado da Rocha, custodiados no Arquivo Histórico do Rio Grande do Sul (AHRS), onde podemos encontrar panfletos emitidos pela Brigada Militar publicados no Jornal Correio do Povo tendo como destino os membros da corporação e inativos, assim como a comunidade rio-grandense no geral, acusações referentes à ligação de parentesco entre Brizola e Jango, assim como panfletos emitidos por Leonel de Moura Brizola em resposta as acusações da Frente Democrática ${ }^{5}$. No campo teórico, seguiremos as orientações da Nova História Política, dadas por Rémond (2003) e Bernstein (2003), do Trabalhismo, dadas por Gomes (1988) e Ferreira (2011) e do Anticomunismo, por Motta (2000) e Rodeghero (1998).

\section{Anticomunismo, Trabalhismo e a Nova História Política}

O historiador francês René Rémond (2003) explica que a nova concepção de história, presente no início do século XX, deixaria de lado a história política, dedicando maior atenção para a história econômica e

\footnotetext{
${ }^{1}$ Líder e fundador da Ação Integralista Brasileira (AIB) e - posteriormente ao golpe - de 1945 do Partido de Representação Popular (PRP).

${ }^{2}$ Militar e político comunista brasileiro, líder PCB.

${ }^{3}$ Militar e político brasileiro, eleito deputado estadual em 1950 e 1954, candidato a governador em 1958 e governador durante a Ditadura Militar.

${ }^{4}$ Doc. APWB - 09.23.13.04 - Acervo Particular Walter Peracchi Barcelos - Arquivo Histórico do Rio Grande do Sul (AHRS)

${ }^{5}$ Coligação formada pelo PSD, PL e UDN.
} 
social. Neste sentido, Peter Burke elenca as mudanças exercidas pela Escola dos Annales ${ }^{6}$ :

Em primeiro lugar, a substituição da tradicional narrativa de acontecimentos por uma história-problema. Em segundo lugar, a história de todas as atividades humanas e não apenas história política. Em terceiro lugar, visando completar os dois primeiros objetivos, a colaboração com outras disciplinas, tais como a geografia, a sociologia, a psicologia, a economia, a lingüística, a antropologia social, e tantas outras (BURKE, 1991, p.7).

Desta maneira, a velha história se torna obsoleta, pois dava evidência somente aos líderes estatais e a história dos vencedores. A história que durante séculos foi hegemônica, era menosprezada e, por anos, mesmo a partir de novas concepções de poder que renovariam o campo, não seria aceita por um grande número de historiadores. Contudo, a partir do desenvolvimento das políticas públicas, a ampliação dos domínios políticos, entre outros processos, os historiadores passaram a se interessar novamente por este campo. Com base nisso, Rémond (2003) afirma:

Os trabalhos de história politica pululam, numerosas teses the são consagradas. O ensino, após ter obedecido à convicção de que se devia descartar a política em beneficio da economia e das relações sociais, tende hoje a reintroduzir a dimensão política dos fatos coletivos (RÉMOND, 2003, p.21).

Rémond (2003, p. 33) entende que a história não desconsidera o tempo em que foi escrita. Sendo assim, o processo político irá afetar o modo como se vê a política. A História Política então volta à demanda dos historiadores, "pois o ato eleitoral ganha uma significação que faz dele o mais sincero e significativo de todos os comportamentos coletivos".

A problemática do nosso trabalho contém partidos consolidados por características específicas e estra- tégias de mobilização do eleitorado. Serge Bernstein explica que, "aos olhos do historiador, o partido aparece fundamentalmente como o lugar onde se opera a mediação política" (BERNSTEIN, 2003, p.60). O autor elenca algumas características de um partido: a duração no tempo, a extensão do espaço, a aspiração ao exercício do poder e a vontade de buscar o apoio junto à população. Sobre a última, Bernstein afirma que ela ocorre através da atração, do convencimento, seguindo o resultado do alcance do poder. Nisso, as campanhas eleitorais tem grande importância. Segundo Rémond:

A campanha é parte integrante de uma eleição, é seu primeiro ato. Não é apenas a manifestação das preocupações dos eleitores ou a explicação dos programas dos candidatos e dos temas dos partidos, é a entrada em operação de estratégias, a interação entre os cálculos dos politicos e os movimentos de opinião. Sobretudo, ela modifica a cada dia as intenções e talvez a relação de forças (RÉMOND, 2003, p.49).

O anticomunismo, peça chave na campanha eleitoral de Walter Peracchi Barcelos, há algum tempo, tem sido discutido no Brasil por diversos autores. Rodrigo Patto de Sá Motta entende os anticomunistas como "indivíduos e grupos dedicados à luta contra o comunismo, pela palavra ou pela ação" (MOTTA, 2000, p.4). O autor explica que esse grupo não estava restrito apenas a extrema direita, mas também a setores liberais e católicos. Para, o anticomunismo passa a ser evidenciado a partir da Revolução Russa, em 1917, tendo seu ápice no contexto da Guerra Fria onde, temporalmente, está situado esse trabalho. No caso brasileiro, com a participação política pós-queda do Estado Novo, a formação de novos partidos políticos, inclusive do PCB, fortaleceria as idéias anticomunistas no cenário nacional. Podemos pensar que a participação da URSS no combate ao nazifascismo alemão contribuiu para um

\footnotetext{
${ }^{6}$ Movimento historiográfico do início do século XX que se destacou por incorporar métodos das Ciências Sociais à História.
} 
sucesso do PCB nas eleições de 1946. Boris Fausto, dissertando acerca disto, escreve que:

O PCB surgia, em 1946, como o quarto partido do país. Elegera dezessete deputados e um senador e alcançara a maioria na Câmara de Vereadores do Distrito Federal. Em São Paulo, os comunistas obtiveram o terceiro lugar no total de votos na eleição estaduais de 1947, superando a UDN. Calcula-se que o partido contava, em 1946, com cerca de 180 a 200 mil militantes (FAUSTO, 2008, p.402).

Para Fausto, o PCB entraria na ilegalidade efetivamente em 1948, sob influência da guerra civil no território da China e da Grécia e o papel hegemônico dos Estados Unidos. Somada a isso, é realizada, em 1947, uma denúncia ao Tribunal Eleitoral na qual o Partido Comunista Brasileiro era acusado de duplo estatuto, sendo intitulado de Partido Comunista do Brasil e não Brasileiro. Foi considerado também na ação o símbolo internacional da foice e do martelo (ASSIS; GONÇALVES, 2009). Mesmo na ilegalidade e com a cassação dos cargos dos membros do PCB, continuariam os adjetivos e ações dos setores conservadores contra o "Perigo Comunista"7, sendo exigidos atestados de ideologia política e declarações contra a doutrina marxista e leninista.

Conforme Motta (2000), os principais teóricos anticomunistas no Brasil, após a Segunda Guerra Mundial, seriam Hoover, Schawarz, James e Decter. Esses autores escreviam manuais, que vieram a se tornar as principais fontes da doutrina anticomunista. Entretanto, tais manuais não seriam seguidos "ipsis literis", sendo adaptáveis à realidade do Brasil a partir dos setores que o compartilhavam. Por exemplo, a associação do comunismo ao "diabo" e de política "contra a cristandade", eram amplamente divulgados pela Igreja Católica. Carla Simone Rodeghero (1998) disserta sobre as estraté- gias utilizadas pelo clero rio-grandense, na divulgação do que conceitua como "imaginário anticomunista". Todavia, segundo Motta (2000) é perigoso classificar o anticomunismo apenas como um "perigo", a todos os políticos anticomunistas como manipuladores e à parcela da população que os apoiava como fanáticos e tolos. O perigo era em parte real, no que diz respeito à ameaça que este representava à Igreja, através da substituição da moral cristã por uma moral "proletária" e aos liberais, pregando o fim da propriedade privada. Portanto, podemos compreender o anticomunismo presente neste momento como algo embasado em uma ameaça até certo ponto "real", e não apenas em fábulas, mas utilizado no âmbito político como forma de promoção e ascensão por parte de indivíduos e partidos.

O PCB, desde sua formação em 1922, esteve ligado à luta em favor da classe trabalhadora, entendida como proletariado, assim como também se fez nos sindicatos e movimentos grevistas. Nesse sentido, a comparação entre a política trabalhista, levando em consideração principalmente seu campo de atuação, no caso o operariado, era algo rotineiro. A questão que se abre é, portanto, como identificar a formação e emergência da política trabalhista frente ao comunismo, assim como as semelhanças e diferenças entre estas, a fim de compreender, conseqüentemente, o discurso anticomunista da Frente Democrática contra o candidato petebista, Leonel de Moura Brizola.

De acordo com Jorge Ferreira (2012), na década de 30 as potências européias encontravam-se enfraquecidas no seu poderio mundial e, neste cenário, surge o nacional-estatismo. Muitos países da periferia do capitalismo, como por exemplo, Brasil, Argentina, Índia e México aproveitaram as brechas deixadas pelas rivalidades entre estas potências neste momento turbulento e

\footnotetext{
${ }^{7}$ Termo utilizado por Motta (2000) como referência ao discurso anticomunista utilizado contra os grupos de esquerda.
} 
encontraram meios de superar a dependência das mesmas, assim como formular projetos que dessem a estes países certo grau de autonomia no cenário mundial. Em cada um desses países, tal projeto recebeu um nome, de acordo com a sua história e tradições políticas. No Brasil, recebeu o nome de trabalhismo. Acerca do projeto político nacional-estatista destes países, Ferreira (2012) afirma:

O projeto era ambicioso: colocar em prática o desenvolvimento nacional autônomo baseado em um Estado forte, centralizado, interventor e planejador; em alguns desses países, mobilizar a população em torno de uma ideologia elou de uma liderança carismática, recorrendo, para isso, a um partido político de caráter nacional; conseguir o apoio de empresários e trabalhadores, e incentivá-los a colaboração mútua (FERREIRA, 2012, p. 308).

Para Ferreira, o nacional-estatismo, implementado no Brasil ainda na década de 30, revelou-se como um projeto nacional em vários sentidos: induziu e financiou a industrialização, procurou valorizar os padrões de cultura do país, gerando assim uma economia moderna com algum grau de autonomia e identidade cultural, além de visar o fortalecimento do Estado e da criação de estatais. Todavia, a política nacional-estatista não visava apenas o empresariado e o Estado. O projeto brasileiro valorizou também a mão de obra, acreditando que "para o desenvolvimento do país, não era mais possível à dilapidação de um importante fator de produção: os trabalhadores" (FERREIRA, 2012, p. 308). Desta forma, leis sociais e políticas públicas referentes à educação e saúde foram colocadas em prática.

Segundo Angela de Castro Gomes (1988), após o fim do Estado Novo, em 1945, tem início no Brasil o processo de redemocratização e, com ele, o surgimento daqueles que seriam os três partidos de maior representatividade no período: União Democrática Nacional (UDN), Partido Social Democrático (PSD) e PTB. O
PTB emerge, segundo Gomes, com um cunho eminentemente sindicalista, com a função de canalizar os esforços investidos por Vargas durante o Estado Novo na organização sindical dos trabalhadores. Conforme Patrizia Piozzi (1983), o PTB surge com o intuito de representar os interesses dos trabalhadores, sendo assim uma alternativa a aqueles que não se identificavam com a direita conservadora ou com a extrema esquerda, comunista. Contudo, diferentemente deste último, oferecia ao operariado uma perspectiva de luta dentro de canais legais, já estabelecidos pelo sistema, por um capitalismo mais justo e humano, onde os empregadores abrem mão de certos privilégios em favor dos trabalhadores, e estes, em contrapartida, renunciam a métodos destrutivos da luta de classes, pregados pelos comunistas. Portanto, podemos compreender o programa político do PTB, na sua origem, tendo como base a defesa dos interesses da classe trabalhadora juntamente com a manutenção da ordem já instituída, dentro da qual os trabalhadores não precisariam recorrer a greves e outros movimentos, pois haveria, na Câmara Federal e no Senado, uma bancada que lutaria incessantemente em favor de suas demandas e por soluções mais rápidas e eficazes.

Desta forma, desde a sua fundação, a desconfiança de setores, sejam de oposição ou de situação, pairavam sobre o PTB e suas ideologias, uma vez que, de acordo Ferreira (2012), os comunistas do PCB, assim como organizações sindicais e outros partidos de esquerda tomaram como bandeira o projeto trabalhista, agregando a ele elementos de caráter reformista, como a ampliação das leis e benefícios sociais, reforma agrária, tradição da unidade sindical, demanda por educação e saúde publica de qualidade, reajustes salariais, a fim de aumentar o poder de compra dos trabalhadores, entre outras. Considerando a ilegalidade na qual se encontrava o $\mathrm{PCB}$, assim como o cenário político nacional e internacional e o apelo anticomunista praticado pelas eli- 
tes conservadoras, se fazia necessário o distanciamento por parte dos trabalhistas do PCB e da figura de Luis Carlos Prestes, seu principal líder. Com base nisso, buscaremos neste trabalho compreender as principais estratégias utilizadas pela Frente Democrática contra o PTB e seu candidato, Leonel Brizola.

\section{A propaganda anticomunista e os ataques ao trabalhismo de Leonel Brizola}

Conforme Mercedes Maria Loguercio Cánepa (2005), a campanha eleitoral da Frente Democrática, da qual Walter Peracchi Barcelos era candidato, girou em torno de uma série de temas principais, utilizados como forma de mobilização eleitoral, dentre eles o apelo anticomunista clássico, a valorização da família e da fé cristã, a crítica à aliança PTB-PRP e ao apoio do PCB a Leonel de Moura Brizola.

Tendo em vista a formação militar do candidato ao Governo do Estado nas eleições de 1958, Walter Peracchi Barcelos, houve intenso apoio por parte do Comando da Brigada Militar do Rio Grande do Sul a sua candidatura. Segundo panfleto publicado pelo Comitê Central dos Inativos da Brigada Militar ${ }^{8}$, situado a época na Rua dos Andradas, 1021, no centro de Porto Alegre, que foi fundado satisfazendo os desejos tanto de oficiais como de praças da Brigada Militar. Tal Comitê ficaria responsável por coordenar o trabalho de outros militares em prol da campanha de Walter Peracchi Barcelos. De acordo com o documento, a reunião de oficialização deste comitê contou com a presença de $280 \mathrm{mi}$ litares, sendo coordenada pelo Coronel Oreste Carneiro da Fontoura. O informativo conclamava ainda a todos os servidores e beneficiários da Brigada Militar, em prol da grandeza do Estado e do Brasil, a votarem e apoiarem a candidatura Walter Peracchi Barcelos nas eleições de três de outubro, fazendo com que cada lar de um policial militar se tornasse um posto avançado pela campanha da Frente Democrática, a fim de estarem prestando mais um grande e precioso serviço à Brigada Militar e ao Rio Grande do Sul, uma vez que a causa abraçada não pertencia a apenas um, mas a todos, e de certa forma se confundia com a causa da própria Brigada, maior do que qualquer outro compromisso que um membro da instituição pudesse ter firmado anteriormente.

Até mesmo as viúvas dos militares foram alvos do Comitê recém-formado, que as lembrava do fato de serem amparadas pelo Montepio Militar ${ }^{9}$, instituído por Walter Peracchi Barcelos quando Comandante Geral. Seu voto e apoio ao candidato da Frente Democrática não significaria apenas gratidão a aquele que não as deixou desamparadas, mas uma forma de honrar também seu ente querido, companheiro de farda do então candidato. Todavia, apesar do discurso moral e em prol do Estado, o objetivo de ver elevado ao mais alto cargo de administrador do Rio Grande do Sul um membro da Brigada Militar, que defendesse e garantisse seus direitos, se fazia presente a todo o momento, colocando muitas vezes a corporação acima do bem estar social. Desejo esse, afirmado em outro panfleto, nominado Mensagem aos sargentos, cabos e soldados inativos da Brigada Militar ${ }^{10}$, onde, em destaque, afirmavam que se eleito, não os faria superior a qualquer outra classe de trabalhadores; todavia, os faria justiça e lhes garantia seus direitos.

No entanto, o apoio militar não se limitou aos portões dos quartéis. Engajados em eleger o candidato que representava a Frente Democrática, utilizaram de

\footnotetext{
${ }^{8}$ Doc. APWB - 09.19.13.04 - Acervo Particular Walter Peracchi Barcelos - Arquivo Histórico do Rio Grande do Sul (AHRS).

${ }^{9}$ Fundo Previdenciário Privado, estabelecido por Peracchi Barcelos enquanto Comandante Geral da Brigada Militar.

${ }^{10}$ Doc. APWB - 09.22.13.04 - Acervo Particular Walter Peracchi Barcelos - Arquivo Histórico do Rio Grande do Sul (AHRS).
} 
sua influência e prestígio adquiridos com o passar do tempo junto ao povo rio-grandense, exaltando o passado de glórias e sua honradez moral em um momento de instabilidade política pelo qual atravessava o estado do Rio Grande do Sul através de comunicados impressos direcionados não somente aos membros da corporação, mas também a comunidade gaúcha. Um exemplo disso é outro panfleto, nominado Proclamação ao Povo do Rio Grande do $S u l^{11}$, onde, além da instituição, a figura de Walter Peracchi Barcelos é elevada a um patamar vultoso de moral e boa conduta. "Homem de sólidos princípios morais", "animado por um profundo espírito humano", "servido por uma alta consciência cívica": esses são apenas alguns dos adjetivos vinculados à figura do candidato da Frente Democrática e transmitidos à população como uma esperança frente ao mal que representava o Comunismo. "Um legítimo representante das tradições da honra, da lealdade e do espírito de patriotismo da Força Pública do Estado"; um simples soldado, que depois de ocupar todos os cargos da hierarquia militar, alcançou destaque no cenário político estadual e nacional. Walter Peracchi Barcelos era, na visão dos conservadores e militares, a figura perfeita capaz de enfrentar os trabalhistas, liderados por Leonel de Moura Brizola e sob a mística de Getúlio Vargas, em uma batalha pelo mais alto posto do Poder Executivo do estado do Rio Grande do Sul.

A propaganda política de Walter Peracchi Barcelos, todavia, não se deteve apenas ao enaltecimento da figura do próprio militar, assim como a Instituição da qual fazia parte. Ataques pessoais ao candidato Leonel de Moura Brizola e ao PTB foram uma constante na campanha eleitoral de 1958 por meio de folhetos impressos, como trovas assinadas por anônimos, mas cla- ramente financiados pela Frente Democrática, como por exemplo, O Mar de Lama, que dá nome ao presente artigo. Nome este que, de acordo Fausto (2008), esteve presente na série de acusações a Getulio Vargas que, apesar de não comprometerem pessoalmente a figura do presidente, permeavam seu Governo, sendo investigado pela polícia e pela Aeronáutica, sendo esta motivada pelo assassinato do Major Ruben Vaz, que acompanhava Carlos Lacerda ${ }^{12}$ durante um atentado a vida do jornalista. Portanto, trata-se de uma clara insinuação aos lados sombrios do Governo de Getulio Vargas, que refletiam diretamente sobre o PTB, do qual era fundador.

Na campanha de 1958 no Rio Grande do Sul, o apelo ao anticomunismo, bem como a valorização da família e da fé cristã e as severas críticas ao apoio do PCB à candidatura do petebista Leonel Brizola constituíram-se, conforme Cánepa (2005), como algumas das principais bases da candidatura Walter Peracchi Barcelos. Estes são os temas principais do poema $O$ Mar de Lama, citado anteriormente, e podem ser observadas em versos como:

No dia 3 de outubro/Vai ferir-se um grande duelo/O povo já se prepara/Com Peracchi Barcelos/Com a igreja e a família/ Contra a foice e o martelo/Uma boa verdade é esta/Está bem a nossa vista/ [...] Isto é uma realidade/Você pode comprovar/Se conhece algum comunista/ Por perto do seu lugar/Você pergunte para ele/Em quem pretende votar/Lá em Porto Alegrel Brizola teve proveito/Mas pergunte àquele povo/Por quem ele foi eleito/O Partido Comunista/Fez o Brizola prefeito. [...] Eleitores do Rio Grande/ Já estão bastante treinados/ Principalmente os colonos/ Que tomem muito cuidado/ Poisque os comunistas estão/ Por Brizola controlados/ Os eleitores coloniais/ Ainda estarão lembrados/ Daquele último pleito/ Para o Governo do Estado/ Comunistas e trabalhistas/ Votaram de braços dados.

\footnotetext{
${ }^{11}$ Doc. APWB - 09.21.13.04 - Acervo Particular Walter Peracchi Barcelos - Arquivo Histórico do Rio Grande do Sul (AHRS).

${ }^{12}$ Jornalista e político brasileiro, membro da UDN. Exerceu o cargo de vereador, deputado federal e governador da Guanabara. Ficou conhecido como um dos principais críticos de Getúlio Vargas.
} 
Com base nos versos acima, verificamos que as acusações de ligação com o PCB são anteriores a 1958 e remetem as eleições municipais de 1954, quando Brizola tornou-se Prefeito de Porto Alegre, assim como as eleições de 1954 para o Governo do Estado, quando Alberto Pasqualini, candidato trabalhista, foi derrotado por Ildo Menegheti. Tais acusações fazem-se presentes também no discurso de apoiadores da Frente Democrática como, por exemplo, o deputado do Partido Socialista Brasileiro (PSB) ${ }^{13}$, Candido Norberto, que remetem à vitória petebista sob um suposto apoio comunista:

O candidato do PTB já recebeu, nas eleições municipais, o apoio dos comunistas e agora o Sr. Leonel Brizola está sendo clara e ostensivamente apoiado pelo Partido Comunista [...] o sr. Brizola administrou e administra a Prefeitura de Porto Alegre, com a solidariedade efetiva de representantes do Partido Republicano, cujas origens de ordem eleitoral são bem conhecidas. O sr. só não levou à presidência da Câmara Municipal de Porto Alegre um vereador que poderá não ser comunista, mas que o Partido comunista está vinculado.

Constatamos, mais uma vez, a partir desta fala, a tentativa de ligação do candidato trabalhista ao PCB, agora não apenas com insinuações acerca de um suposto apoio comunista nas eleições de 1955 à Prefeitura de Porto Alegre, quando foi eleito, mas também de favorecimento aos mesmos durante sua gestão na Capital, tendo como intermediário o Partido Republicano, no qual os comunistas se encontrariam supostamente infiltrados.

A valorização da família e da fé cristã, outro alicerce da campanha de Walter Peracchi Barcelos, está diretamente relacionada ao anticomunismo, e consequentemente, às críticas ao apoio do PCB ao PTB, tendo como base, a tentativa de substituição da moral cristã por moral "proletária", assim como a associação dos comunistas ao "diabo", referida anteriormente. Para Cánepa (2005), isto se fazia ainda mais necessário neste momento, uma vez que eram também bandeiras do PRP, coligado no pleito de 1958 ao PTB. Pode ser percebida, por exemplo, no poema citado anteriormente, $O$ Mar de Lama, quando, nos seus versos iniciais, o autor faz menção à "luta" que seria travada no pleito de 3 de outubro onde, de um lado estaria Walter Peracchi Barcelos, com a igreja e a família, e de outro a foice e o martelo, representados por Leonel Brizola e seus apoiadores comunistas. Além disso, percebemos tais aspectos em inúmeras manifestações de Walter Peracchi Barcelos, como por exemplo, o Impressionante e Comovente Discurso de Peracchi ${ }^{14}$, noticiado no Jornal Correio do Povo, no qual o candidato do PSD declara:

Nascido em berço humilde, aprendi, desde cedo, no ambiento modesto em que formei as linhas mestras do meu caráter, a resguardar, com pudor e respeito, todos aqueles preceitos de honestidade, que ouvi da boca de meu pai e senti nos exemplos de minha mãe. [...] Procuraram ferir a honra de um homem ferindolhe, antes, a dignidade da própria familia. [...] A vós, mães e esposas, que mantendo ainda essa velha e exemplar condição de pureza moral, que a fé cristã vos autorga, a vós, esposas e mães do Rio Grande, eu dedico toda a calada resignação com que a minha esposa e mãe dos meus filhos vem vivendo esse quadro de insultos à honra do seu lar.

Percebemos, a partir dos versos, a nítida tentativa de mobilização popular através de conceitos como a família - seja pela ação nostálgica de lembrar a infầcia, pai e mãe, quanto por colocar, como possíveis alvos dos ataques recebidos, sua família - e fé cristã - na qual a família tradicional está enraizada - alvos dos comunistas, ligados a Brizola.

\footnotetext{
${ }^{13}$ Doc. APWB - 13.169.26.11 - Acervo Particular Walter Peracchi Barcelos - Arquivo Histórico do Rio Grande do Sul (AHRS).

${ }^{14}$ Doc. APWB - 13.171.26.11 - Acervo Particular Walter Peracchi Barcelos - Arquivo Histórico do Rio Grande do Sul (AHRS).
} 
Frente aos ferrenhos ataques, presentes desde eleições para a prefeitura de Porto Alegre em 1955, como se pode verificar no poema, entendem-se, de acordo com Cánepa (2005), “a presteza e a rigidez com que Brizola se preocupa em repudiar tal apoio, ainda que defenda a legalização do PC.” Apoio este expresso pelo principal líder comunista, Luis Carlos Prestes, noticiado em reportagem ao Jornal $A$ Hora ${ }^{15}$, frente à impossibilidade de se candidatar pelo PCB, em consequência da ilegalidade na qual se encontrava o partido, afirma:

Aceitarei por qualquer um. Naturalmente o mais dificil de aceitar seria o PRP, pelo seu passado de integralistas, mas mesmo com o PRP nós estamos prontos a marchar juntos, no Rio Grande do Sul, apoiando a candidatura do senhor Leonel de Moura Brizola, Nós aceitaríamos qualquer legenda.

Diante das acusações por parte da Frente Democrática, Brizola recusou o apoio de Prestes, a fim de não perder os votos católicos na região da serra gaúcha (BRAGA et al. 2004), e aproveitou, nesta ocasião, para expor as diferenças entre o trabalhismo:

[...] o trabalhismo é nacionalista, o comunismo é internacional; o comunismo é materialista, o trabalhismo se inspira na doutrina social cristã; o comunismo é a abolição da propriedade, o trabalhismo defende a propriedade dentro de um fim social; o comunismo escraviza o homem ao Estado e prescreve o regime de garantia de trabalho, o trabalhismo é a dignificação do trabalho e não tolera a exploração do homem pelo Estado nem do homem pelo homem; o comunismo educa para formar uma sociedade de formigas, o trabalhismo educa para o progresso, para a liberdade, para a elevação da pessoa humana (BRAGA et al. 2004, p. 50).

Apesar do repúdio ao apoio comunista, Luis Carlos Prestes não mudou seu posicionamento quanto à candidatura trabalhista. Segundo Cánepa (2005), em entrevista a Rádio Itaí, dias antes das eleições, o líder comunista reiterou seu apoio à candidatura de Brizola, com o intuito de derrotar Walter Peracchi Barcelos, a quem chamou de "o candidato do entreguismo". De acordo com Prestes, seu apoio não dependia da vontade de Leonel Brizola. Apoiava a candidatura trabalhista porque, para derrotar um, era necessário apoiar o outro.

A ligação de parentesco entre Brizola e o então Vice-Presidente da República, João Goulart, também foi alvo de acusações por parte da Frente Democrática e fica explicita em outra trova, intitulada ...e a FLAUTA pegou! ${ }^{16}$ assinada pelo trovador "Gaúcho Velho", que diz: "Brizola! Brizola!/ Não adianta choradeira/ Morreu a vaca Ita/ Vais mamar numa terneira!/ Brizola! Brizola!/ Não adianta a choradeira/ Vai pedir a João Goulart/ Que te arranje outra terneira”. Uma insinuação de que o candidato trabalhista se fazia valer da proximidade com Jango e do status que tal posição lhe trazia para alçar vôos maiores, rumo ao Palácio Piratini.

Tal ligação de parentesco fortalecia ainda mais as acusações de proximidade entre Brizola e os comunistas, uma vez que o nome de Jango fora ligado ao PCB enquanto Ministro do Trabalho, pois conforme Angela de Castro Gomes e Maria Celina D’Araújo (1989), ao liberalizar a política sindical, buscou uma reaproximação desta classe com o PTB, abrindo, ao mesmo tempo, um campo de atuação para o PCB, visando uma ação conjunta entre estes e os trabalhistas. A partir desta ação, os comunistas passaram a gozar de uma margem de liberdade oficiosa para atuar entre a classe trabalhadora que não possuíam desde 1946, quando o partido entrou na ilegalidade. De acordo com Gomes e D'Araújo (1989), a estada de Goulart no Ministério do Trabalho foi tida como a possibilidade de estabelecimento de uma república sindicalista, devido,

\footnotetext{
${ }^{15}$ Maço 61 - Acervo Particular Francisco de Paula Brochado da Rocha - Arquivo Histórico do Rio Grande do Sul (AHRS).

${ }^{16}$ Doc. APWB - 09.15.13.04 - Acervo Particular Walter Peracchi Barcelos - Arquivo Histórico do Rio Grande do Sul (AHRS).
} 
entre outras coisas, ao aumento da participação dos trabalhadores na política e ao crescimento do trabalhismo.

Sendo assim, a proximidade com o VicePresidente fazia de Brizola um alvo de acusações de oportunismo, assim como de favorecimento a idéias e estabelecimento do PCB no Rio Grande do Sul e em todo o território nacional, remetendo-nos ao anticomunismo e às acusações de ligação ao partido liderado por Luis Carlos Prestes, citadas anteriormente.

Ataques à coligação PTB-PRP, de igual maneira, fizeram parte da pauta de campanha de Walter Peracchi Barcelos contra os trabalhistas. Para Cánepa, estas críticas sobrepassaram toda a campanha eleitoral e estão embasadas em dois argumentos: "Quanto à aliança PTP -PRP, envolve dois aspectos: alguns apontam a incongruência e o oportunismo da mesma, e outros, como é o caso do Partido Libertador, se concentram no caráter totalitário e, portanto, antidemocrático do integralismo" (CÁNEPA, 2005, p.245).

Tal aliança era, de acordo com Cánepa (2005), almejada já em janeiro de 1958 pelos trabalhistas. O PTB, em carta encaminhada à convenção do PRP, fez referência aos pontos em comum para um plano de Governo, afirmando que nenhuma subordinação ocorreria em caso de vitória dos trabalhistas e ressaltando que contava com a participação da agremiação, PRP, nas responsabilidades do Governo. Em janeiro do mesmo ano, tal aliança foi consolidada. A partir daí, iniciou-se uma campanha massiva, por parte da Frente Democrática, no intuito de denegrir a coligação, que juntamente com o PSP, ficaria conhecida como Frente Popular.

No que se refere à incongruência e ao oportunismo desta união, a Frente Democrática explorou uma série de discursos e ofensas proferidas por membros do PTB contra o PRP, e vice versa, no intuito de pôr em atrito eleitores de ambos os partidos. Tais acusações estão presentes em $O$ Mar de Lama, como nos mostram os versos abaixo:

[...] Nós estamos confirmando/ $O$ que dizem os integralistas// Foram eles que disseram/ Que o PTB é comunista [...] O PRP do Rio Grande/Talvez não seja culpado/Plínio que fez essa união/Deve estar descontrolado/Os PRP andam dizendo/Que estão mal acompanhados/O PRP pobrezinho/Não devemos maldizer/Mas unido ao PTB/Vai deixar-se comprometer/Porque uma ovelha ruim/Bota o rebanho a perder.

Outro exemplo de acusação, baseada no caráter oportunista da coligação, é a declaração do deputado Cândido Norberto, do PSB, referidas anteriormente, na qual justifica o apoio do partido à Frente Democrática. Nela, disse não se fazer valer de qualquer compromisso ou concessão de ordem doutrinária, diferentemente de outros partidos - PTB e PRP - que até ontem proclamavam existir entre si divergências intransponíveis, porém, agora, andavam lado a lado, negociando direitos e interesses. Declarou ainda não ser trabalhista para, entre um democrata e um integralista, escolher, em troca de vantagens eleitorais, o segundo, e que, além de todos os motivos apontados até agora, teriam contra a candidatura integralista tudo aquilo que, no passado, o próprio Leonel Brizola disse acerca desta agremiação.

Quanto às acusações referentes ao caráter totalitário e antidemocrático do PRP, adjetivos como "integralistas" e "fascistas", se tornaram rotineiras em manifestações de integrantes da Frente Democrática quando questionados acerca da aliança PTB-PRP e podem ser verificadas em declarações, como a de Brito Velho, candidato ao Senado pelo PL, em entrevista ao Jornal Correio do Povo, na qual afirma: "o dirigente máximo do Partido da Representação Popular, e naturalmente seus seguidores apresentam-se falsamente como democratas, devendo ser classificados entre os totalitários da direita". 
Plínio Salgado, a quem Brito Velho se refere, era, em 1958, a principal liderança do PRP a nível nacional. Porém, sua ligação com os integralistas era inegável, sendo um dos fundadores da Ação Integralista Brasileira (AIB) - movimento político fascista nacionalista brasileiro -, em 1932, logo após a Revolução Constitucionalista $^{17}$, na cidade de São Paulo (FAUSTO, 2008). Trata-se, portanto, de uma clara tentativa de retomar o período em que esteve em atividade a AIB trazendo a tona assim o passado antidemocrático não apenas de Plínio, mas de inúmeros outros membros do PRP que integraram este movimento.

Além destas, acusações como as de ligação com o comunismo também fizeram parte do vasto repertório de ataques da Frente Democrática à coligação PTBPRP. Para os apoiadores de Walter Peracchi Barcelos, tratava-se de uma cortina de fumaça, que tinha como intuito esconder os verdadeiros apoiadores de Leonel Brizola: os comunistas. Tais acusações podem ser percebidas, por exemplo, em declarações, como a publicada do Jornal Folha da Tarde ${ }^{18}$, que noticia: “A despeito dos falsos repúdios a chamada Frente Populista (PTBPRP-PSP) está unida ao comunismo. É um antigo conluio, agora repudiado apenas para iludir o eleitorado católico".

Apesar destas acusações, tal união foi defendida de todas as formas por Brizola, ocupando por vezes considerável tempo do seu discurso em rádios. Para o candidato trabalhista, as acusações ao PRP eram infundadas e maliciosas e que a pluralidade de partidos políticos, e consequentemente, de ideologias políticas estava assegurada na Constituição e fazia parte de um sistema democrático. Segundo recorte do Jornal Correio do Povo, conforme Cánepa (2005), declarou não conside- rar o PRP um partido de direita. Disse ainda considerar de direita outras forças políticas nacionais, reacionárias, como o Partido Liberal (PL) e o chamado "lacerdismo" da UDN.

A defesa de tal aliança, de forma tão veemente por Leonel de Moura Brizola, pode ser explicada pelo fato de ser considerada uma das bases da campanha trabalhista, uma vez que seria a garantia de votos em áreas onde o PTB possuía pouca penetração (BRAGA et al. 2004). Ideia também compartilhada por Cánepa (2005). Segundo a autora, através de exames de materiais divulgados pela imprensa da época, observa-se que, mesmo antes do lançamento formal da plataforma de Governo, a campanha de Brizola já girava em torno de uma série de temas principais, incluindo a legitimidade da aliança com o PRP. Além disso, uma aliança com o PRP, tido como um partido conservador e de direita afastariam, em parte, os rumores de uma possível ligação entre Brizola e os comunistas, que o acompanhavam desde as eleições para a prefeitura de Porto Alegre em 1955.

Outra maneira encontrada pela Frente Democrática para combater o trabalhismo foi, de maneira contundente, lembrar o Estado Novo. Neste período, de forte repressão a organizações políticas e manifestações culturais internacionais, o Governo Vargas promoveu uma integração forçada dos alemães, que de maneira isolada, cultivavam suas origens e costumes. Os teutobrasileiros, segundo Santos (2007), representavam uma imensa ameaça ao projeto político introduzido por Getulio após 1937, que pregava uma cultura estritamente brasileira e combatia todo tipo de diversidade cultural, seja ela manifestada através da língua, da música ou qualquer outro costume mantido por imigrantes no Bra-

\footnotetext{
${ }^{17}$ Movimento armado, ocorrido no município de São Paulo, com o intuito de derrubar o Governo provisório de Vargas.

${ }^{18}$ Doc. 02.01.01.15 - Maço 15 - Acervo Particular Hamilton Moojen Chaves - Arquivo Histórico do Rio Grande do Sul (AHRS).
} 
sil. Passaram assim a representar uma ameaça, não só a nação brasileira, mas a todos os países da América do Sul, dada a política expansionista de Adolf Hitler. Com a entrada do Brasil na guerra, em 1942, os imigrantes alemães e italianos passaram a ser vistos como inimigos do Estado, traidores e espiões. A perseguição policial, outrora não declarada, era agora legitimada, uma vez que todo imigrante alemão ou italiano era tido como um provável colaborador do Eixo (SANTOS, 2007). Com base nestes fatos, foram publicados, em $O$ Mar Lama, versos como:

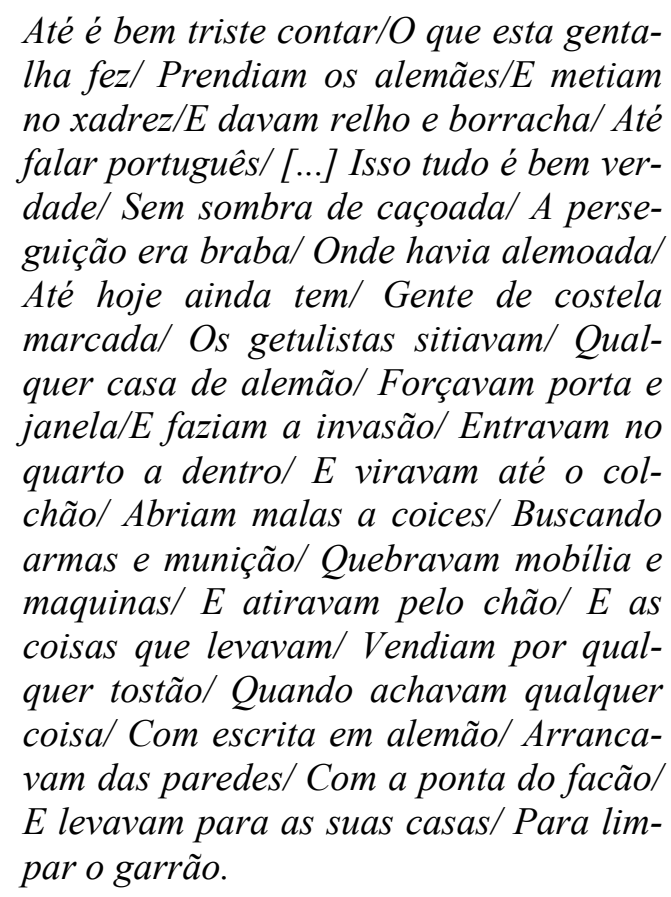

Estes versos, entre outros, traziam à tona a política ditatorial getulista para com os imigrantes e atingiam diretamente a candidatura de Leonel Brizola, considerado um dos herdeiros políticos de Vargas, além de pôr em cheque a credibilidade do PTB frente aos imigrantes, que eram, na sua grande maioria, fiéis eleitores do PRP e que possuíam grande representatividade no Interior e Serra gaúcha. Um movimento estratégico, diante da grande possibilidade de sucesso - que veio a se concretizar no final do pleito eleitoral de 1958 - que tal coligação possuía.
Tão logo as acusações acerca da perseguição aos colonos alemães no período do Estado Novo - que automaticamente recaíam sobre os trabalhistas, e mais especificamente sobre Brizola - foram divulgadas, veio o contra-ataque por parte dos mesmos. Em um panfleto intitulado Lembrai-vos do Tempo da Guerra!... ${ }^{19}$, Walter Peracchi Barcelos foi alvo de incriminações de teor semelhante às praticadas por ele. Aproveitando-se do passado do candidato militar, tal panfleto possuía o intuito de lembrar que, no mesmo período em que acusava o Estado Novo, na figura de Vargas, de perseguição e maus tratos a colonos, o então candidato da Frente Democrática atuou como Chefe da Casa Militar do Interventor Cordeiro de Farias, autorizando a invasão de casas, assim como o confisco de rádios, espingardas, relógios, coleções de moedas, Bíblias, entre outras coisas. O panfleto reiterava ainda que ninguém, sob nenhuma hipótese, estava autorizado a falar na língua da pátria de origem. Aqueles que se opunham a tal ordem eram surrados e presos por soldados da polícia militar gaúcha, subordinados a Walter Peracchi Barcelos.

Da mesma maneira que as acusações contra os getulistas, no Estado Novo, recaiam sobre Brizola, tais acusações contra o candidato do PSD não atingiam apenas a ele, mas a instituição Brigada Militar, a qual este representava, podendo ser compreendidas como retaliação ao apoio declarado do Comando da Brigada ao candidato da Frente Democrática. Segundo o panfleto Lembrai-vos do Tempo da Guerra!..., o mesmo coronel que naquele momento se apresentava como uma ovelha mansa, angariando votos daqueles que chamava de amigos e buscava a simpatia através da religião, levando em consideração a força do cristianismo em meio aos colonos de maneira geral, outrora fora um lobo, que juntamente com outros, comiam e tiravam tudo que os colonos, com muita luta, haviam conquistado.

\footnotetext{
${ }^{19}$ Doc. APWB - 09.18.13.04 - Acervo Particular Walter Peracchi Barcelos - Arquivo Histórico do Rio Grande do Sul (AHRS).
} 


\section{Considerações Finais}

Através desta análise, entendemos o anticomunismo como um dos principais alicerces da campanha da Frente Democrática no pleito de 1958 pelo Governo do Estado do Rio Grande do Sul. O anticomunismo manifestou-se de maneira variada através de práticas e discursos, indo ao encontro da análise de Motta (2000) acerca do tema no país, adaptado de acordo com realidade brasileira a partir dos setores que o compartilhavam. Identificamos, neste caso, acusações de ligação e apoio aos ideais comunistas, referentes tanto ao momento presente, mediante ao apoio declarado pelo líder do PCB, Luis Carlos Prestes, quanto a um passado próximo, onde Brizola, segundo seus acusadores, foi beneficiado pelo apoio comunista, se elegendo naquela ocasião prefeito da capital gaúcha, assim como críticas as alianças políticas estabelecidas, mais especificamente entre PTB e PRP, destacando o passado integralista do seu principal líder, Plínio Salgado, e o caráter fascista do partido frente ao discurso trabalhista. Além disso, constatamos a ação nostálgica de lembrar a perseguição praticada contra imigrantes alemães e italianos durante o Estado Novo por Vargas, fundador do PTB, atacando de forma direta o legado de Getúlio, principal bandeira trabalhista, bem como insinuações acerca de possíveis benefícios que uma ligação com o Vice Presidente, João Goulart, traziam a Brizola, além de novamente ligar a figura do petebista aos comunistas, dadas as ações tomadas por Jango, seu cunhado, enquanto Ministro do Trabalho, que veio a beneficiar os trabalhadores de modo geral, e consequentemente aos comunistas. Para além das acusações diretas ao candidato trabalhista e ao próprio PTB, percebemos uma intensa campanha junto a órgãos públicos como a Brigada Militar, da qual Walter Peracchi Barcelos fazia parte, utilizando o prestígio da mesma para fortalecimento da imagem do candidato da Frente Democrática frente ao eleitorado riograndense.
Verificamos, a partir daí, o anticomunismo não exclusivamente como uma convicção ideológica, mas como um discurso que buscava mobilizar as massas, referido por Motta (2000) como uma prática frequente, mas não generalizada, entre políticos conservadores. Estes utilizavam o medo crescente de uma parcela da população, decorrente do crescimento de partidos de esquerda em âmbito nacional e estadual, como forma de alavancar suas carreiras políticas ou, neste caso, obter sucesso no pleito eleitoral, fazendo-se valer de diversos meios midiáticos, como jornal e rádio, a fim de se mostrarem à população como ferrenhos combatentes do perigo comunista - que atentava contra a moral cristã, os bons costumes e à família. Foi o caso de Walter Peracchi Barcelos, que se apoiou sobre um discurso que apela a ideias ligadas à moral, aos princípios cristãos e à família, além da credibilidade que o posto de militar lhe oferecia.

Por fim, percebemos, diante de fortes acusações e respostas, distribuição de panfletos e larga mobilização, um cenário extremamente competitivo e um sistema político significativamente mais democrático, frente à ampliação e mudança de perfil do eleitorado, que se tornava cada vez mais urbano, com mais acesso a informação e, conseqüentemente, mais crítico. Desta forma, a disputa por cada voto se tornava cada vez mais intensa. Além disso, verificamos que, como foi relatado, até mesmo o apoio de determinado partido ou figura política, neste caso o PCB e seu líder, Luis Carlos Prestes, poderia significar a derrota em uma campanha, consequência da perda dos votos de determinada parcela da sociedade e que, a fim de gerar o distanciamento de imagem em relação aos comunistas, alianças com partidos ideologicamente opostos eram tidas como vitais, demonstrando assim a não existência de um jogo de cartas marcadas, mas de um cenário político volátil, passível de mudanças a todo instante. 


\section{Referências Bibliográficas}

ASSIS, Laura de Oliveira; Gonçalves, Leandro Pereira, 2009. A Renovação Pecebista nos Anos 50: um projeto inspirado na ideologia Gramsciana. Revista Labor: $\mathrm{n}^{\circ}$ 2, v.1.

BERSTEIN, Serge. Os Partidos. In: RÉMOND, René. Por Uma História Política. Rio de Janeiro: Editora FGV, 2003.

BRAGA, Kenny; SOUZA, João B.; DIONI, Cleber; BONES, Elmar.(Org.). Leonel Brizola: perfil, discursos e depoimentos (1922-2004). Porto Alegre: Assembléia Legislativa do RS, 2004.

BURKE, Peter. A Escola dos Annales (1929-1989): a revolução francesa da historiografia. São Paulo: Editora UNESP, 1992.

CÁNEPA, Mercedes Maria Loguercio. Partidos e Representação Política: a articulação dos níveis estadual e nacional no Rio Grande do Sul (1945-1965). Porto Alegre: Editora da UFRGS, 2005.

FAUSTO, Boris. História do Brasil. 13. Ed. São Paulo: Editora da Universidade de São Paulo, 2008.

FERREIRA, Jorge. Os conceitos e seus lugares: trabalhismo, nacional-estatismo e populismo. In: BASTOS, Pedro Paulo Zahluth, FONSECA, Pedro Cesar Dutra (Org). A Era Vargas: Desenvolvimentismo, economia e sociedade. São Paulo: Editora Unesp, 2012.

GOMES, Angela de Castro. A Invenção do Trabalhismo. Rio de Janeiro: Vértice JUPERJ, 1988.

GOMES, Angela de Castro; D’ARAÚJO, Maria Celina. Getulismo e Trabalhismo. São Paulo: Editora Ática, 1989.

MOTTA, Rodrigo Patto de Sá. Em Guarda Contra o Perigo Vermelho: o anticomunismo no Brasil. São Paulo, Tese (Doutorado) - Faculdade de Filosofia, Letras e Ciências Humanas da USP. Universidade de São Paulo, 2000.

PIOZZI, Patrizia. 1983. Vargas e Prestes: Uma comparação entre o Trabalhismo e o Comunismo no Brasil. Revista Transformação, v.6, 1983, p. 25-36.

RÉMOND, René (org.). Por Uma História Política. Rio de Janeiro: Editora FGV, 2003.

RODEGHERO, Carla Simone. O Diabo é Vermelho: imaginário anticomunista e Igreja Católica no Rio Grande do Sul (1945-1964). Passo Fundo: Editora UPF, 1998.

SANTOS. Fabiane dos, 2007. A construção do inimigo: é tempo de guerra, medo e silêncio. Revista Santa Catarina em História: v.1, n.2, 62-72.

\section{Fontes Documentais}

Doc. 02.01.01.15 - Maço 15 - Acervo Particular Hamilton Moojen Chaves - Arquivo Histórico do Rio Grande do Sul (AHRS).

Maço 61 - Acervo Particular Francisco de Paula Brochado da Rocha - Arquivo Histórico do Rio Grande do Sul (AHRS).

Doc. APWB - 09.15.13.04 - Acervo Particular Walter Peracchi Barcelos - Arquivo Histórico do Rio Grande do Sul (AHRS).

Doc. APWB - 09.18.13.04 - Acervo Particular Walter Peracchi Barcelos - Arquivo Histórico do Rio Grande do Sul (AHRS).

Doc. APWB - 09.19.13.04 - Acervo Particular Walter Peracchi Barcelos - Arquivo Histórico do Rio Grande do Sul (AHRS).

Doc. APWB - 09.21.13.04 - Acervo Particular Walter Peracchi Barcelos - Arquivo Histórico do Rio Grande do Sul (AHRS). 
Doc. APWB - 09.22.13.04 - Acervo Particular Walter Peracchi Barcelos - Arquivo Histórico do Rio Grande do Sul (AHRS).

Doc. APWB - 09.23.13.04 - Acervo Particular Walter Peracchi Barcelos - Arquivo Histórico do Rio Grande do Sul (AHRS).

Doc. APWB - 13.169.26.11 - Acervo Particular Walter Peracchi Barcelos - Arquivo Histórico do Rio Grande do Sul (AHRS).

Doc. APWB - 13.171.26.11 - Acervo Particular Walter Peracchi Barcelos - Arquivo Histórico do Rio Grande do Sul (AHRS).

Submissão: $22 / 05 / 2016$ Aceite: $25 / 10 / 2016$ 